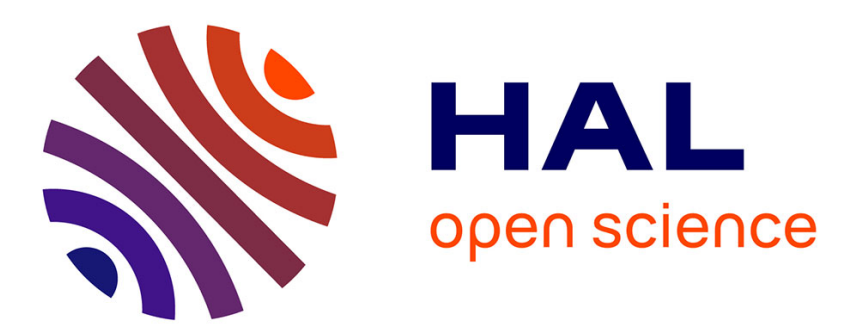

\title{
Effects of strain rate and temperature on the mechanical behavior of high-density polyethylene
}

Abderrahmane Lamri, Mohammadali Shirinbayan, Michael Pereira, Laurianne

Truffault, Joseph Fitoussi, Saad Lamouri, Farid Bakir, Abbas Tcharkhtchi

\section{- To cite this version:}

Abderrahmane Lamri, Mohammadali Shirinbayan, Michael Pereira, Laurianne Truffault, Joseph Fitoussi, et al.. Effects of strain rate and temperature on the mechanical behavior of high-density polyethylene. Journal of Applied Polymer Science, 2020, 137 (23), pp.48778. 10.1002/app.48778 . hal-02545697

\section{HAL Id: hal-02545697 \\ https://hal.science/hal-02545697}

Submitted on 17 Apr 2020

HAL is a multi-disciplinary open access archive for the deposit and dissemination of scientific research documents, whether they are published or not. The documents may come from teaching and research institutions in France or abroad, or from public or private research centers.
L'archive ouverte pluridisciplinaire HAL, est destinée au dépôt et à la diffusion de documents scientifiques de niveau recherche, publiés ou non, émanant des établissements d'enseignement et de recherche français ou étrangers, des laboratoires publics ou privés. 


\title{
Effects of strain rate and temperature on the mechanical behavior of high-density polyethylene
}

\author{
Abderrahmane Lamri, ${ }^{1,2,3}$ Mohammadali Shirinbayan $\mathbb{0}^{1,2}$ Michael Pereira, ${ }^{2}$ Laurianne Truffault, ${ }^{1}$ \\ Joseph Fitoussi, ${ }^{1}$ Saad Lamouri, ${ }^{3}$ Farid Bakir, ${ }^{2}$ Abbas Tcharkhtchi ${ }^{1}$ \\ ${ }^{1}$ Arts et Métiers ParisTech, PIMM - UMR CNRS 8006, 151 Boulevard de I'Hôpital, 75013, Paris, France \\ ${ }^{2}$ Arts et Métiers ParisTech, DynFluid, 151 Boulevard de l'Hôpital, 75013, Paris, France \\ ${ }^{3}$ Unité d'Etude et Recherche des Procédés Energétiques (UERPE), Ecole Militaire Polytechnique (EMP), Alger, Algeria \\ Correspondence to: M. Shirinbayan (E-mail: mohammadali.shirinbayan@ensam.eu)
}

\begin{abstract}
The objective of this work is to initiate the discussion about multiphysics relationships between the molten and solid states of high-density polyethylene (HDPE). The extrusion and the injection processes are employed to prepare samples, and the experimental procedures, using differential scanning calorimetry, dynamic thermomechanical analysis (DMTA), thermal gravimetric analysis, and rheological measurements, are defined to choose the optimal variables. After different characterizations, the extrusion and injection temperatures of 220 and $230{ }^{\circ} \mathrm{C}$ have been chosen. To investigate the viscoelastic behavior of HDPE, the DMTA is used. To perform the high strain rate tensile tests, tensile machine was equipped with a specific furnace. Two temperatures, -20 and $20{ }^{\circ} \mathrm{C}$, with strain rates varying from 0.001 to 100 seconds $^{-1}$ were used to compare the flow characteristics. Results showed that by increasing the strain rate the molecular mobility of the HDPE chains is decreased. In addition, to the tests at $-20{ }^{\circ} \mathrm{C}$, the increase of Young's modulus can be prop-erly
\end{abstract} observed, under high strain rates.

\section{INTRODUCTION}

The development of plastic materials with specific properties allowing them to replace traditional materials like steel or wood has massively contributed to the growth of consumption of these materials. However, some of the most widely used polymers like polyolefin are inherently easier to employ than traditional materials. $^{1-5}$ In fact, innovations searched are those that preserve the benefits of cost reduction, lightness, and ease of processing.

Polyethylene (PE) is frequently used in the plastics and especially for recycling cable covering because of its abrasion resistance, flexibility, excellent electric insulation properties, low toxicity, and easy processing. High-density polyethylene (HDPE) goes on one type of typically found in bags and refillable bottles. ${ }^{5-8}$ HDPE is used to manufacture lumber, garden goods, buckets, crates, office products, and automobile parts. It possesses several properties that make it ideal as a packaging and manufacturing product. HDPE is stronger than standard PE, acts as an effective barrier against moisture, and remains solid at ambient temperature..$^{5-8}$

Polymers can be exposed to a many reprocessing that may affect their process ability and quality of products. ${ }^{9,10}$ During extrusion which is the principal industrial process applied to PE, it is exposed to high shear stresses and temperatures, which can cause its degradation. Many researchers have been interested on various types of polyolefin, using different rheological models in the molten state. ${ }^{11-14}$ They typically present the influence of branched polymers on the complex modulus. Some of these works show the dependency of storage modulus, loss modulus, and phase angle on the polymer molecular structure..$^{9-15}$

The properties of the polymers are unpreserved during their treatment due to degradation by heat, mechanical stress, and oxidation. The degradation affects the structure of the molecule and consequently the quality of the material. Quality is, therefore, the crucial problem when using recycled products. Indeed, during the recycling operations in addition to the incidence on the mechanical properties, the rheological characteristics are also modified. This causes a direct effect on performance of products and must be taken into account during processes. ${ }^{11-13}$

Rheological factors are sensitive to structural changes in polymer chains. ${ }^{16}$ It is necessary to have more information about polymer properties at various temperatures applications and equally diverse loading conditions. To achieve these goals, the 
history of the product must be examined. The multiphysics relationship between the states of melting and solid of HDPE is studied here. The development of the appropriate conditions of the process leads to the achievement of the desired mechanical properties.

Various experimental studies have been carried out to identify the mechanical behavior as a function of temperature and strain rate. A great deal of attention has been performed to the yield stress. ${ }^{17-21}$ Kolsky $^{19}$ identified the importance of sample thickness on the test results under high-speed loading. The strain hardening behavior of glassy polymers is dependent on the strain rate and temperature.

Chou et $a .^{20}$ analyzed the compressive behavior of several polymers and concluded that the temperature rise induced during deformation cannot be disregarded. They showed that the elasticity limit increases with the stress rate. Briscoe and Nosker ${ }^{21}$ reported similar results for flow stress.

Many authors ${ }^{17-21}$ have investigated the effect of strain rate on the behavior of several polymers at ambient temperature. In contrast, the influence of temperature at high strain rate has received much less attention. Milisavljević performed a PE tensile test with a nominal strain rate of $40 / \mathrm{s}$. The results showed the Young's modulus is increased by increasing the strain rate. ${ }^{22}$ Tensile behavior of PE revealed the necking phenomenon. The necking of PE was affected by the scattering of mechanical energy as heat, which can elevate the temperature in the neck, causing significant softening; and the deformation resistance of the neck, which has a higher strain rate than the surrounding polymer. The deformation resistance can rise because of the strain-rate dependence of the yield stress.

Testing at temperatures above glass transition temperature $\left(T_{g}\right)$ on thermoplastics and other polymers has shown that both the loading modulus and peak flow stress decrease with increasing temperature. $^{23}$ Based on a study of the miscibility of crystalline and amorphous phases in the solid state, we analyze the relationship between the rheological and mechanical properties of HDPE.

At various conditions of loading such as low or high strain rates and the main applied temperature, the behavior of HDPE is not the same. This question has headed us to assess the coupling effect of temperature and strain rate. In accordance with the standard use of HDPE in distinct climatic zones, two temperatures of -20 and $20{ }^{\circ} \mathrm{C}$ are chosen. Through the common high strain rate machines, the tests at ambient temperature can be performed because of launching system. In this work, a specific furnace was installed to the machine for performing the tests at $-20^{\circ} \mathrm{C}$. The effect of strain rate on the characteristics of HDPE coupled with the influence of temperature is therefore studied.

The organization of this paper is as follows: after a presentation of the essential physical-chemical characteristics and microstructure of HDPE selected, its thermomechanical properties and its viscoelastic behavior will be studied. The results of the quasistatic and high strain rate tensile tests up to failure are presented. Scanning electron microscopy (SEM) fractography emphasizes the effect of loading conditions.

\section{MATERIAL PREPARATION AND METHODS}

\section{Polyethylene}

$\mathrm{PE}$ belongs to the vast family of polyolefin ${ }^{15}$ and is the synthetic polymer that remains the most coherent chemical structure. The HDPE-N-211, used in this study, is provided by Matrix-Polymer as a semicrystalline powder. This material possesses a density of about $0.96 \mathrm{~g} / \mathrm{cm}^{3}$, it is appropriate for injection molding, and can easily flow under suitable conditions.

\section{Characterization Methods: Process Optimization}

Granulometry Analysis. A vibrating screen brand "Distribution Granulometrique Cilas 920 Liquide," consisting of several sieves of various dimensions was used to control the particle size distribution of PE.

Microscopic Observations. The scanning electron microscope HITACHI 4800 SEM makes it possible to qualify the microstructure of the material and particularly the fractured surfaces of the tensile specimens.

Differential Scanning Calorimetry Test. Differential scanning calorimetry (DSC) Q10 V9.0 apparatus was utilized to find out thermal transitions. Samples of $6.2 \mathrm{mg}$ of mass were first heated from $40{ }^{\circ} \mathrm{C}$ up to $200{ }^{\circ} \mathrm{C}$ and are then cooled to $40{ }^{\circ} \mathrm{C}$, with the rate of $2{ }^{\circ} \mathrm{C} / \mathrm{min}$.

Thermal Gravimetric Analysis. The thermal gravimetric analysis (TGA) method represents one technique allowing in measuring the mass variations of a sample as a function of temperature. Applied to the field of polymers, this technique makes it possible to monitor phenomena like degradation or evaporation. The evolution of the mass of HDPE samples was realized using TGA Q500 apparatus. Cycles were executed in nitrogen atmosphere $(40 \mathrm{~mL} / \mathrm{min})$, of the ambient temperature to $300{ }^{\circ} \mathrm{C}$ with a rate of $10^{\circ} \mathrm{C} / \mathrm{min}$. The initial mass of a sample, put in $\mathrm{Al}_{2} \mathrm{O}_{3}$-crucible of $85 \mu \mathrm{L}$, was $12.32 \mathrm{mg}$. This test provides information about the thermal stability of the polymer.

Rheological Measurement. Anton Paar MCR 502 rheometer was used to measure the rheological properties of the extruded HDPE granulates then molten. This apparatus uses parallel and coaxial plates of diameter and gap equal 25 and $1 \mathrm{~mm}$, respectively. The viscosity and the shear stress of the melted samples are measured at 190,205 , and $220^{\circ} \mathrm{C}$. These samples were subjected to a specific cycle of controlled deformation in the viscoelastic linear region with a frequency sweep of 0.1 at $100 \mathrm{~Hz}$.

\section{Process for Producing the HDPE Plate}

PE granules prepared were introduced into a single-screw extruder Yvroud-Thermoscientifique's. The essential dimensions of this machine are as follows:

- Length of the pumping zone (L) $160 \mathrm{~mm}$.

- Outside diameter (D) $26 \mathrm{~mm}$.

- Inside diameter (d) $20 \mathrm{~mm}$.

- Step of the screw (B) $20 \mathrm{~mm}$.

- Net width (e) $0.26 \mathrm{~mm}$.

- Depth of supplying a section (h) $3.9 \mathrm{~mm}$. 
Then, DK CODIM 175/410 machine was used to press with a clamping force of $1750 \mathrm{kN}$ for performing injection molding.

\section{Thermomechanical and Mechanical Characterization}

Dynamic Thermomechanical Analysis. Dynamic thermomechanical analysis (DMTA) tests were performed using a Dynamic Mechanical Analyzer type Q800 V21.2 TA Instruments. Rectangular specimens with the specific dimensions of $45 \times 4 \times 3 \mathrm{~mm}^{3}$ are used. The sample is clamped at both ends and either flexed in the middle (dual cantilever). The tests are carried out at temperature range of $-125-75^{\circ} \mathrm{C}$ and, at various frequencies of $0.1-30 \mathrm{~Hz}$ in constant amplitude. The storage and loss modulus are measured as function of temperature.

Mechanical Behavior: Tensile Test from Quasistatic to High Strain Rate. Quasistatic tensile tests by the velocity of $2 \mathrm{~mm} / \mathrm{min}$ are performed with a MTS machine. Tensile tests were performed at two temperatures of -20 and $20^{\circ} \mathrm{C}$, assigning to the usetemperature of $\mathrm{PE}$. In addition, high-speed tensile tests were realized with a Schenk Hydropuls VHS 5020 servohydraulic machine, as specifications of the manufacturer. This machine can reach a crosshead speed range from $10^{-4}$ to $20 \mathrm{~m} / \mathrm{s}$. The load level is measured by a piezoelectric crystal load cell having a capacity of a $50 \mathrm{kN}$.

The specimen dimensions are defined as in Figure 1. The value of the thickness is $3 \mathrm{~mm}$. These characteristics of the specimen allow reducing the stress-wave effects in the general response and to generate homogenized stress field during the quasistatic and high-speed tensile tests.

High-strain rate tensile tests are performed at different strain rates until the polymer specimen failure. The testing machine is equipped with a launching system. The specimen is positioned between the load cell (upper extremity) and the moving device (lower extremity) as sketched in Figure 2. A FASTCAM-APX RS high-speed camera (contactless technique) is used to measure the local deformation.

\section{EXPERIMENTAL RESULTS AND DISCUSSION}

\section{Physicochemical Characterization}

Before extrusion and injection processes, different physicochemical characterizations were performed to optimize the process parameters.

Microstructure Analysis. For morphological characterization, samples are analyzed with SEM. Figure 3 shows the particle size

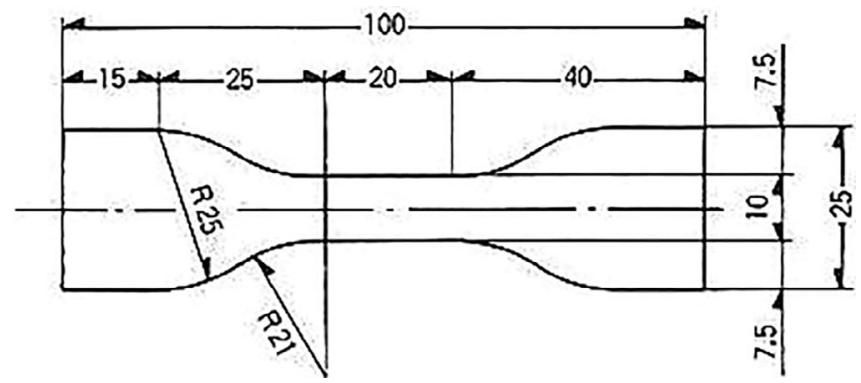

Figure 1. Dimensions of HDPE samples.

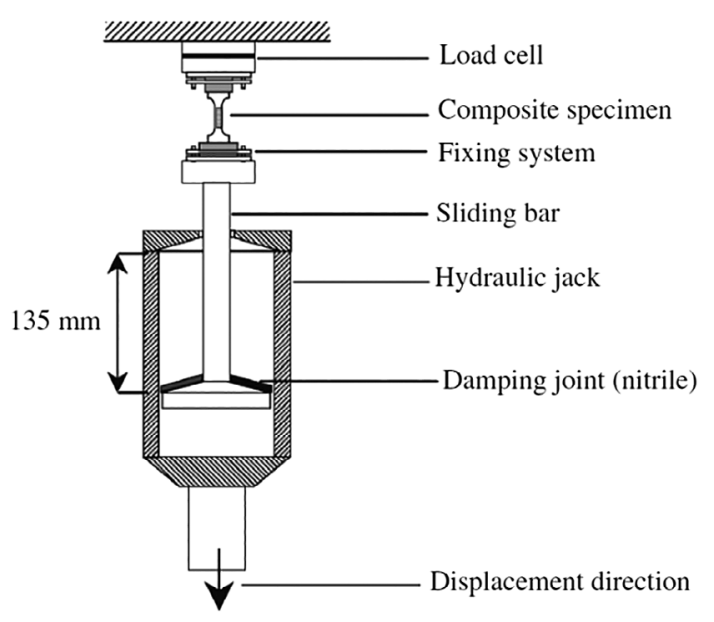

Figure 2. Experimental device used for high-speed tensile tests.

of the HDPE powders. One can notice that there are different particle sizes, which confirms it is necessary to do the granulometry analysis before the production process.

Granulometry Analysis. A vibrating screen (Distribution Granulometrique Cilas 920 Liquide) consisting of several sieves of varied sizes is used to control the particles size distribution of HDPE. Figure 4 presents the obtained results. It can be mentioned that this initial HDPE is composed of grains of between 25 and $500 \mu \mathrm{m}$ and that its distribution keeps a maximum at about $365 \mu \mathrm{m}$. In this study, the grain size of $200 \mu \mathrm{m}$ was selected by sieving.

DSC Analysis. DSC is employed to test the present polymer, HDPE-N-211. Figure 5 shows that this HDPE has a crystallization and melting temperatures of 110 and about $124^{\circ} \mathrm{C}$, respectively. The extruder temperature is around $210^{\circ} \mathrm{C}$. In addition, because of technical limitations of the DSC apparatus, it is not possible to find the $T_{g}$. Indeed, this is lower than the ambient

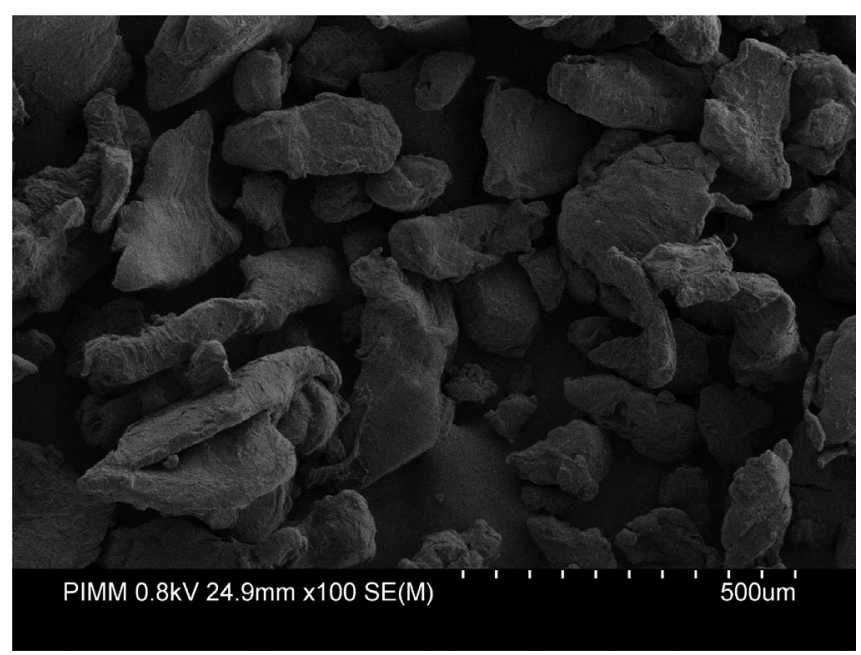

Figure 3. SEM micrograph of HDPE. 


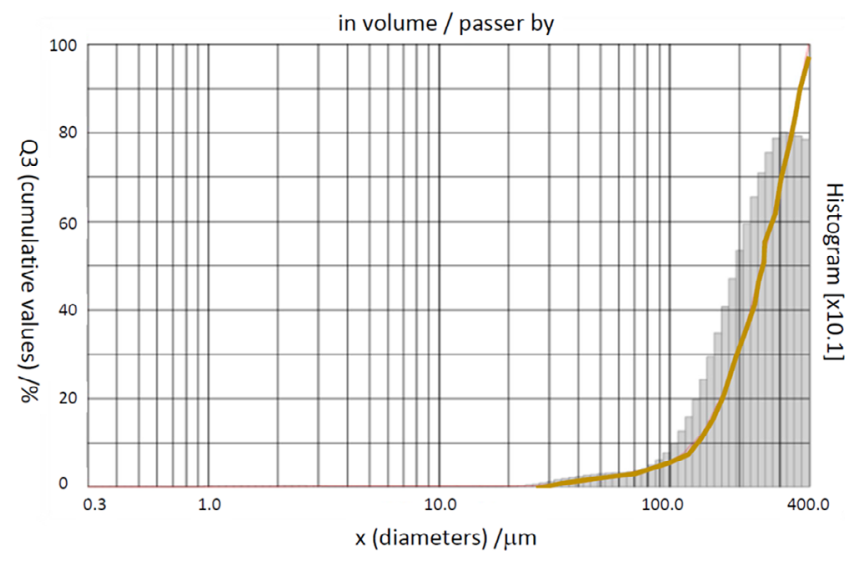

Figure 4. Particles size distribution of HDPE. [Color figure can be viewed at wileyonlinelibrary.com]

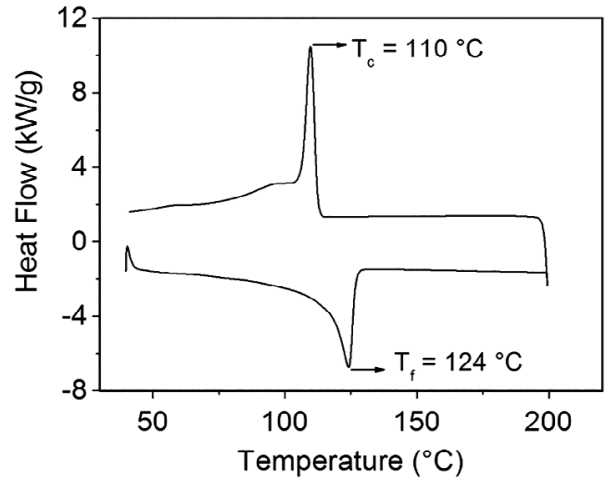

Figure 5. DSC results for HDPE.

temperature and is around $-110{ }^{\circ} \mathrm{C}$. It is for this reason that the DMTA analysis has been carried out.

TGA Characterization. The TGA curve of the HDPE is given in Figure 6. The results show that this HDPE has no significant weight loss before $130{ }^{\circ} \mathrm{C}$. The sample lost nearly $2 \%$ of its initial weight between this last and $350^{\circ} \mathrm{C}$. From $280^{\circ} \mathrm{C}$ approximately, the kinetics weight loss changes, suggesting another mechanism. In view of these TGA results, according to process time, it can be concluded that the initial degradation temperature of the HDPE is about $300{ }^{\circ} \mathrm{C}$, well above the material processing temperature, $230^{\circ} \mathrm{C}$.

Rheological Measurements. Curves of apparent viscosity versus shear viscosity are given at various temperatures for HDPE

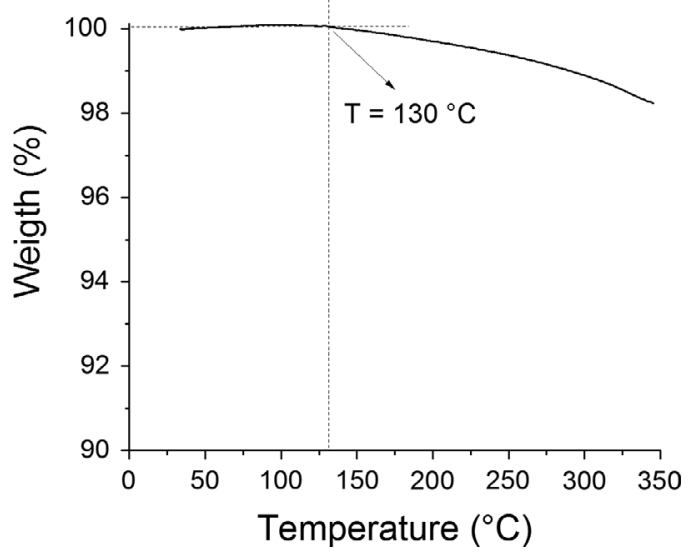

Figure 6. TGA curve of HDPE.

sample in Figure 7. These curves reveal a first region, called Newtonian region where the viscosity does not depend on the shear rate, from $10^{-3} \mathrm{~s}^{-1}$ to approximatively $2 \mathrm{~s}^{-1}$. At $190{ }^{\circ} \mathrm{C}$, the zero shears rate viscosity $\left(\nu_{0}\right)$ is about $3.5 \times 10^{3}$ Pa.s. This value decreases with temperature, as expected for thermoplastics for which zero shear rate viscosity follows Arrhenius law. In our case, the linear dependence of $\ln (\nu 0)$ with $1 / \mathrm{T}$ confirmed that zero shear rate viscosity and temperature are linked by an Arrhenius equation. From the slope of the curve, activation energy for flow of $35.7 \mathrm{~kJ} / \mathrm{mol}$ is found.

At a higher shear rate, viscosity starts decreasing with shear rate. This region distinguishes the shear-thinning behavior of HDPE. During the process, molten polymers present shear-thinning properties due to the high shear rate value existing in the extruder die. The shear-thinning region is better investigated performing dynamic test in the linear viscoelastic region. Figure 8 presents complex viscosity, shear storage modulus $\left(\mathrm{G}^{\prime}\right)$, and shear loss modulus $\left(\mathrm{G}^{\prime \prime}\right)$ as a function of frequency, at $190^{\circ} \mathrm{C}$. In the analyzed angular frequency range, $G^{\prime \prime}$ is higher than $G^{\prime}$ showing viscous behavior predominates and $G^{\prime}$ and $G^{\prime \prime}$ linearly vary with angular frequency.

\section{Process Parameters}

Using the results of thermal and rheological analysis, the extrusion and injection process parameters were defined. One can note that, initially, a sufficient amount of PE granules is dried in an oven to eliminate any residuary moisture. Extrusion process was performed at $220{ }^{\circ} \mathrm{C}$ with flow rate of $500 \mathrm{~g} / \mathrm{h}$ with a screw speed of $150 \mathrm{rpm}$. At the exit, the material extruded passes through a cooling bath. Finally, the product passes into a granulator.

Table I. Different Properties and Process Parameters of HDPE

\begin{tabular}{|c|c|c|c|c|}
\hline$T_{g}$ & $T_{m}$ & $T_{c}$ & $T_{\text {with no weight loss }}$ & Grain size \\
\hline$-125^{\circ} \mathrm{C}$ & $124^{\circ} \mathrm{C}$ & $110^{\circ} \mathrm{C}$ & Before $130^{\circ} \mathrm{C}$ & Up to $200 \mu \mathrm{m}$ \\
\hline \multicolumn{3}{|c|}{ Temperature of extrusion process } & \multicolumn{2}{|c|}{ Temperature of Injection process } \\
\hline \multicolumn{3}{|c|}{$220^{\circ} \mathrm{C}$} & \multicolumn{2}{|c|}{$230^{\circ} \mathrm{C}$} \\
\hline
\end{tabular}




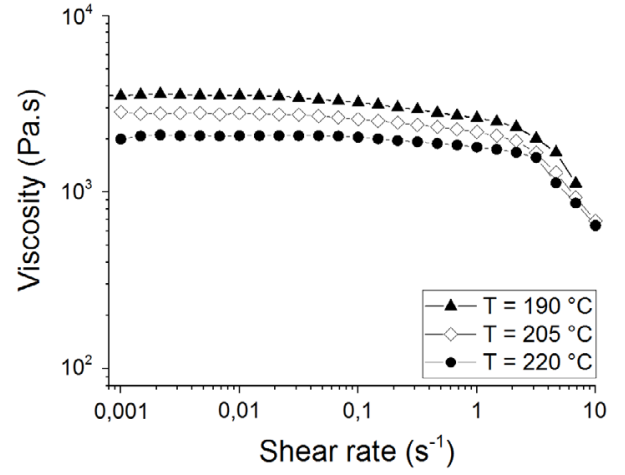

Figure 7. Steady shear viscosities of HDPE at various temperatures as a function of shear rate.

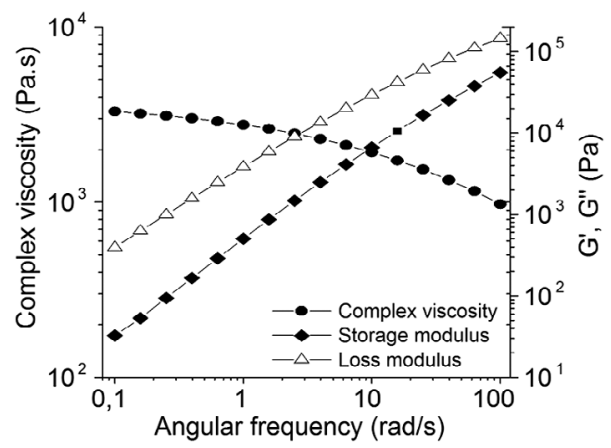

Figure 8. Complex viscosities, storage, and loss modulus of HDPE at $190^{\circ} \mathrm{C}$ as a function frequency.

Once the granules prepared, they are dried in an incubator before being injected. The temperature is set at $230{ }^{\circ} \mathrm{C}$ with an injection speed of $15 \mathrm{~mm} / \mathrm{s}$. The temperature of the mold is held at $50{ }^{\circ} \mathrm{C}$ to allow good crystallization of the material. Finally, HDPE plates having $125-125-2.5 \mathrm{~mm}^{3}$ as dimensions are got after a cooling time of $6 \mathrm{~s}$.

One can conclude that, after different characterization methods, Table I presents different properties and process parameters of HDPE.

\section{Thermomechanical Properties}

DMTA Measurement. DMTA test is preferentially performed to study the different transition temperatures $\left(\mathrm{T}_{\alpha}, \mathrm{T}_{\beta}\right.$, and $\left.\mathrm{T}_{\gamma}\right)$ and change of physical state of the polymer. In this work, DMTA tests have been performed according to the alternating bending configuration in the temperature range between -120 and $75^{\circ} \mathrm{C}$. Figure 9 shows that the storage modulus continuously decreases with increasing the temperature. The value of $\alpha$ transition temperature as measured at tan $\delta$ peak is equal to $-125^{\circ} \mathrm{C}$.

All three curves $E^{\prime}, E^{\prime \prime}$, and $\tan \delta$ show three states of HDPE: glassy state, glass transition zone (called also $\alpha$-transition), and rubbery state. The $T_{g}$ value is conditioned by chain flexibility (segment length), on the main and side chain structure. $T_{g}$ of HDPE is low because of its high chain flexibility and the absence of side groups. Additionally, HDPE is semicrystalline due to its relatively classic and symmetrical structure; therefore, it exhibits

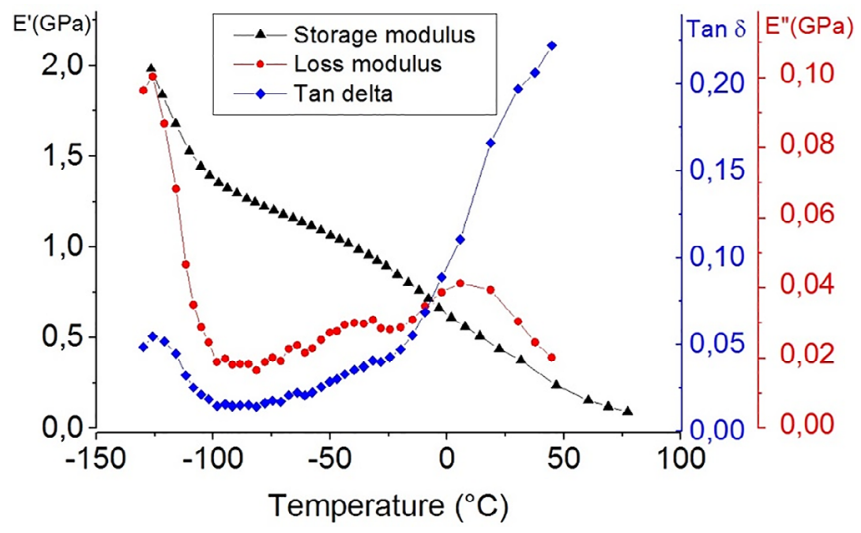

Figure 9. DMA curve of HDPE, frequency $=0.1 \mathrm{~Hz}$. [Color figure can be viewed at wileyonlinelibrary.com]

plastic behavior between $T_{g}$ and $T_{m}$. From this result, it can be exposed that HDPE exhibits a glassy state up to about $-125^{\circ} \mathrm{C}$. The second zone, between -125 and $-100{ }^{\circ} \mathrm{C}$, is $\alpha$-transition zone. It corresponds to the glass transition phenomenon. In this zone, $\mathrm{E}^{\prime}$ decreases from $2000 \mathrm{MPa}$ to a value lower than $1300 \mathrm{MPa}$. The rubbery state of HDPE, is then in the zone of temperature higher than $-100{ }^{\circ} \mathrm{C}$. As it can be mentioned, the value of $\mathrm{E}^{\prime}$ in this state is limited and the sample is relatively soft.

WLF Equation: Free Volume Fraction Calculation. To have a successful modeling and simulation of forming process of plastic, it is essential to know the viscoelastic behavior of the used materials. For example, in extrusion and injection processes, it is important to know the alteration of the viscosity versus the temperature. To explore the effect of temperature on viscoelastic properties of HDPE, multifrequencies DMTA test is conducted on HDPE specimens in bending mode and the results are shown in Figure 10. One can notice that when increasing frequency, the $\alpha$-transition temperature, $T_{\alpha}$ (related to $T_{g}$ ) has an increasing trend to high temperatures.

As mentioned, the viscoelastic behavior of the polymer is related to the frequency of applied loading. This dependence between temperature and proportional viscosity to frequency may be explained by Williams-Landel-Ferry (WLF) equation:

$$
\operatorname{Ln} \frac{f}{f_{r}}=-\frac{C_{1}\left(T-T_{r}\right)}{C_{2}+\left(T-T_{r}\right)}
$$

where $f$ is the frequency, $T$ is the temperature, $f_{r}$ is the reference frequency $(0.1 \mathrm{~Hz})$, and $\mathrm{T}_{\mathrm{r}}$ is the reference temperature.

$$
\mathrm{C}_{1}=\frac{\mathrm{B}}{\mathrm{f}_{\mathrm{g}}} \text { and } \mathrm{C}_{2}=\frac{\mathrm{f}_{\mathrm{g}}}{\Delta \alpha}
$$

where $\mathrm{B}$ is the constant near to $1, \Delta \alpha$ is the thermal expansion coefficient $\left(1.08 \times 10^{-4}\right)$, and $f_{g}$ is the free volume fraction.

To validity of this equation, the linear regression method is used and $\frac{1}{\operatorname{Ln} \frac{f}{f_{r}}}$ is plotted versus $\frac{1}{\left(T-T_{r}\right)}$. If this plot is linear having $A=\frac{C_{2}}{C_{1}}$ 

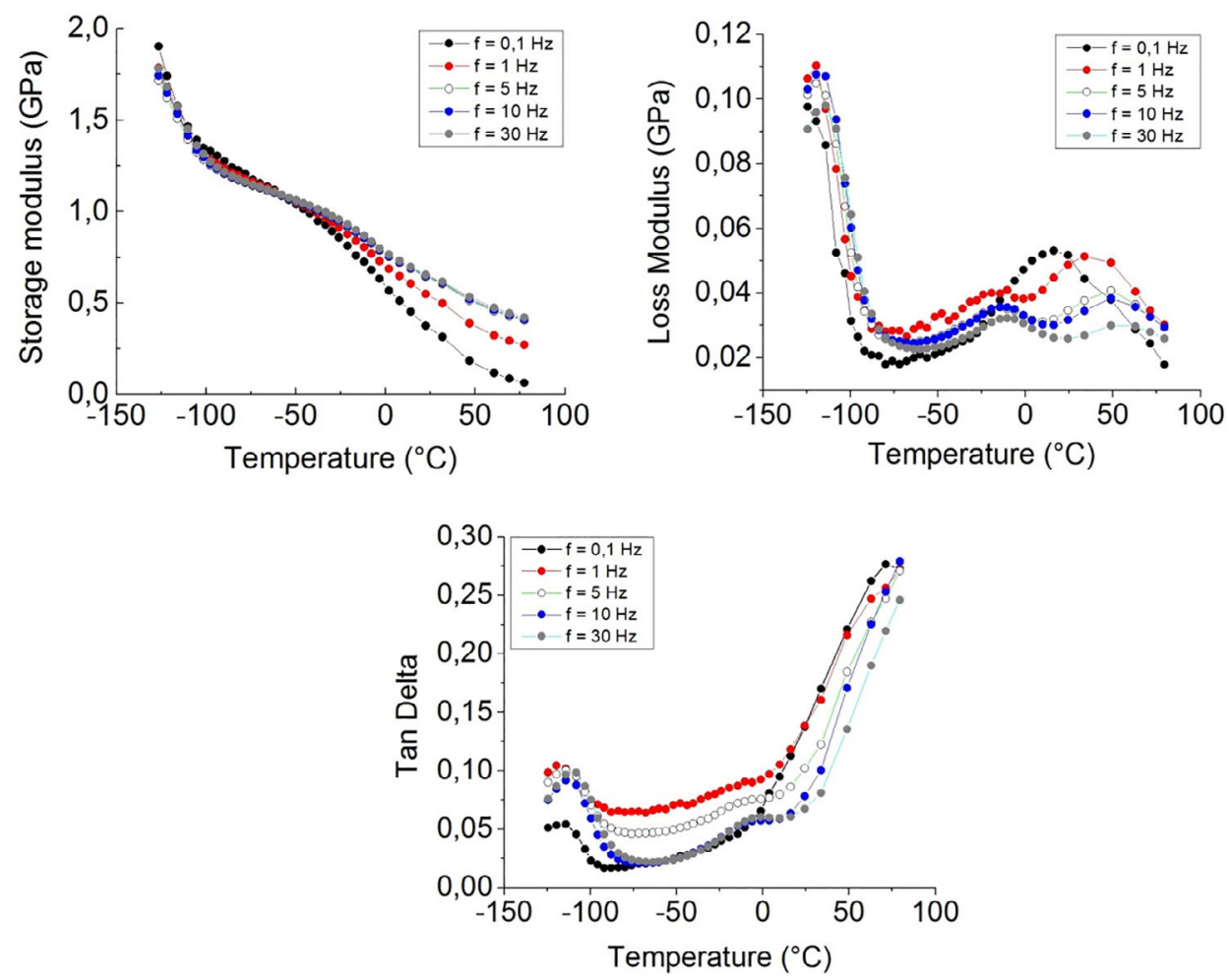

Figure 10. Multifrequencies DMA curves of HDPE. [Color figure can be viewed at wileyonlinelibrary.com]

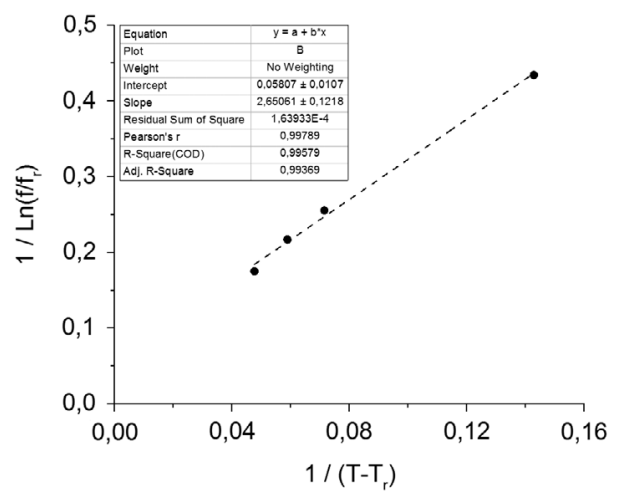

Figure 11. Linear regression of WLF equation on the results issued from the DMTA tests.

as slope, then the validity of the WLF equation is checked. Figure 11 shows the results of linear regression. The linear regression coefficient is almost $1\left(\mathrm{R}_{2}=0.995\right)$. Therefore, the value of free volume fraction coefficient for $\mathrm{HDPE}$ by using $\left(\mathrm{f}_{\mathrm{g}}=\sqrt{B . \Delta \alpha \cdot A}\right)$ is about $1.95 \times 10^{-2}$. The value of $\mathrm{C}_{1}, \mathrm{C}_{2}, \mathrm{f}_{\mathrm{g}}$, and $\Delta \alpha$ is shown in Table II. This means that HDPE under this study obeys the time-temperature equivalence principle.

Table II. The Values of WLF Constants

\begin{tabular}{llll}
\hline $\mathrm{C}_{1}$ & $\mathrm{C}_{2}$ & $\mathrm{f}_{\mathrm{g}}$ & $\Delta \alpha$ \\
\hline 17.22 & 60.75 & $1.95 \times 10^{-2}$ & $1.08 \times 10^{-4}$ \\
\hline
\end{tabular}

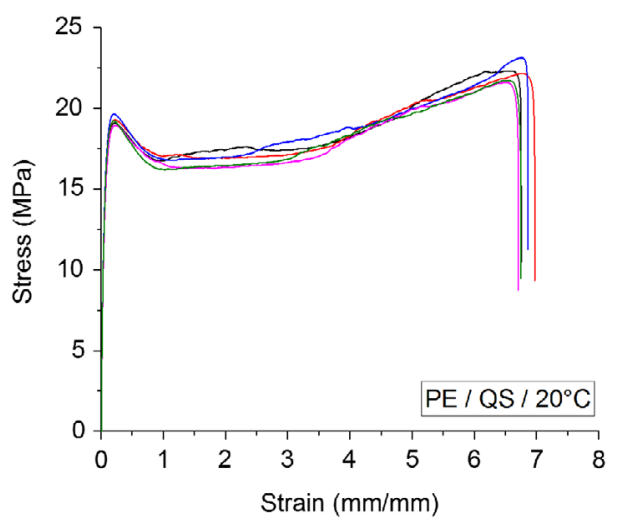

Figure 12. Representative curves of quasistatic tensile tests. [Color figure can be viewed at wileyonlinelibrary.com]

\section{Tensile Behavior of HDPE}

For each test, about five samples are analyzed and the stressstrain curves carried out are repeated many times, one example is done in Figure 12. One can notice there is a good repeatability of tensile behavior of the HDPE samples.

Effect of Temperature. To estimate the effect of temperature on the mechanical properties of HDPE, tensile tests are performed at -20 and $20^{\circ} \mathrm{C}$. The results are presented in Figure 13 and Table III.

One can note that, at first, the HDPE behaves as a linear elastic solid. After the linear part, the yield point can be seen which indicates the onset of plastic deformation. Beyond the yield point 

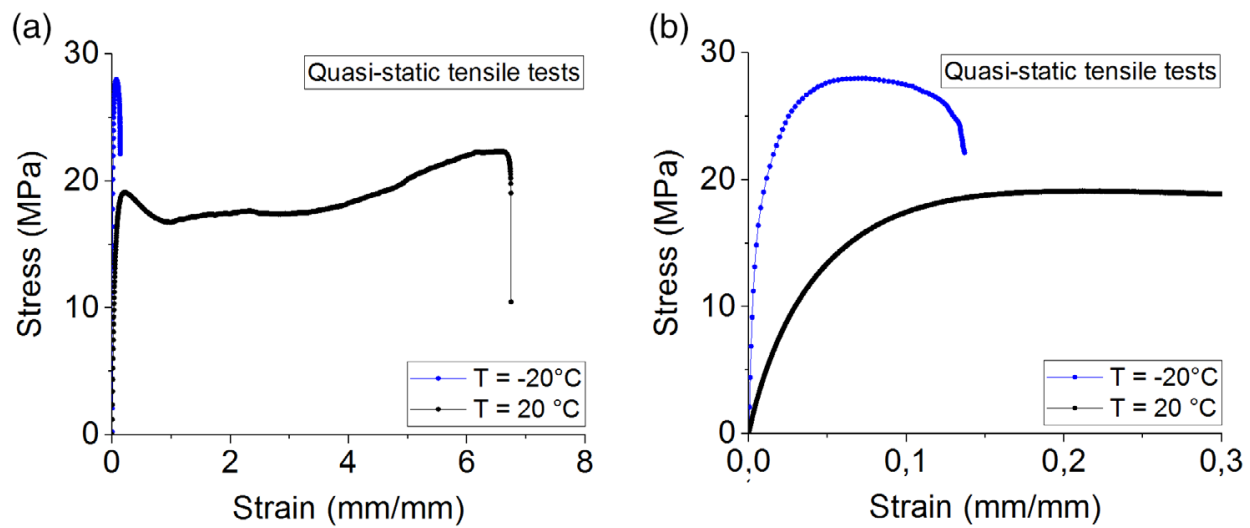

Figure 13. Figure 13 Tensile response of HDPE samples at 20 and $-20{ }^{\circ} \mathrm{C}$. [Color figure can be viewed at wileyonlinelibrary.com]

Table III. Mechanical Characteristics at Different Temperatures

\begin{tabular}{llll}
\hline & $E(\mathrm{MPa})$ & $\sigma_{\max }(\mathrm{MPa})$ & $\varepsilon_{\mathrm{r}}(\mathrm{mm} / \mathrm{mm})$ \\
\hline $20^{\circ} \mathrm{C}$ & 800 & 19 & 6.8 \\
$-20^{\circ} \mathrm{C}$ & 2000 & 27 & 0.14 \\
\hline
\end{tabular}

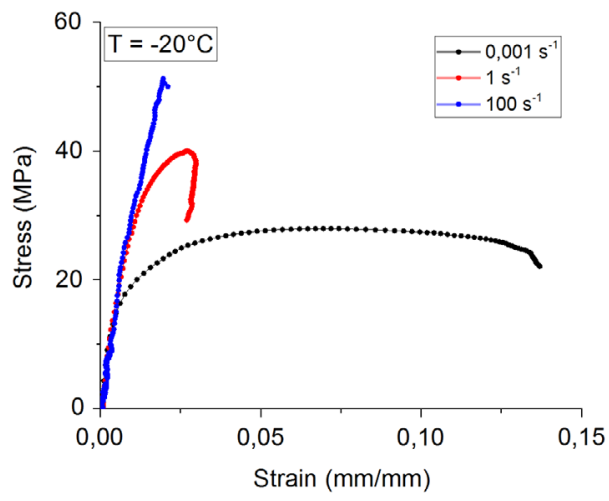

Figure 14. Representative curves of different strain rates tensile tests at $-20^{\circ} \mathrm{C}$. [Color figure can be viewed at wileyonlinelibrary.com]

the HDPE stretches out considerably and a "striction" is typically formed. The striction stabilizes and typically begins to extend. Then, during the alignment and orientation of the polymer chains, which is called strain hardening, the striction will typically continue to thin down until it breaks.

For HDPE samples, the effect of temperature on Young's modulus as well as on yield stress and strain at break is significant. The variation of the temperature from -20 to $20{ }^{\circ} \mathrm{C}$, leads to an abrupt lessening of the Young's modulus from 2000 to $800 \mathrm{MPa}$. While stress at break decreased by $30 \%$ which this effect is more significant, nearly 50 times. The behavior of HDPE depends strongly on the temperature. HDPE is in the "same " rubbery state at -20 and +20 . The progressive melting of some crystallite as the temperature gets closer to the melting point can explain the differences in modulus observed at -20 and $+20{ }^{\circ} \mathrm{C}$.

Effects of Strain Rate on the HDPE Characteristics

Strain rate effect at $-20{ }^{\circ} \mathrm{C}$. Figure 14 shows the stress-strain

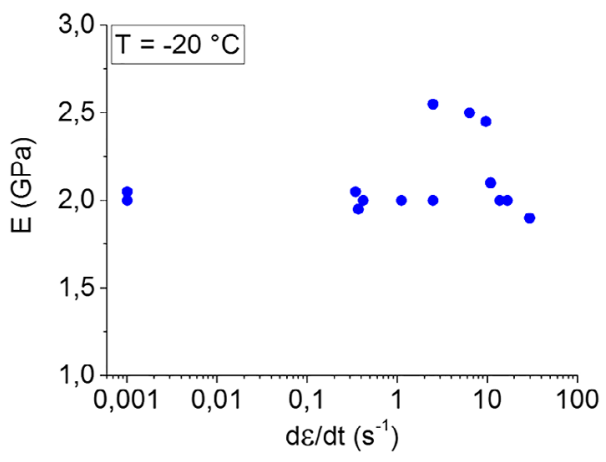

Figure 15. Influence of strain rate on the elastic modulus. [Color figure can be viewed at wileyonlinelibrary.com]

tensile curves $(\sigma-\varepsilon)$ for several strain rates at $-20{ }^{\circ} \mathrm{C}$. We observe the general behavior of HDPE is influenced by the loading rate. Indeed, under the effect of the rapid tensile load, the HDPE is endowed with a high point of flexion. In addition, a material failure occurs rapidly, after the first step. In contrast of the quasistatic curves, these of the high strain rates at the beginning of the second step, have a delay of the knee point and an ultimate stress. By increasing the stress rate to $100 \mathrm{~s}^{-1}$, the breaking stress decreases by about $85 \%$, indicating that the material exhibits brittle behavior.

One can note that increasing strain rate will decrease the molecular mobility of the HDPE chains by making the chains stiffer.

Material characteristics, namely, Young's modulus (E), damage thresholds corresponding to the first nonlinearity ( $\sigma_{\text {threshold; }}$ $\left.\varepsilon_{\text {threshold }}\right)$ and ultimate stress and strain $\left(\sigma_{\text {ultimate }} ; \varepsilon_{\text {ultimate }}\right)$ as a function of strain rate are shown in Figures 15 and 16.

Note that the ultimate characteristics correspond to the maximum stress level. Figure 15 shows that the modulus of elasticity of HDPE, at the first stage of the stress-strain curve, increases slowly with the strain rate.

It is noticeable from Figure $16(\mathrm{a}, \mathrm{c})$ that damage threshold in term of stress and strain increase with strain rate. Figure 16(b) shows that by increasing the strain rate from quasistatic to $100 \mathrm{~s}^{-1}$ maximum stress is increased about $90 \%$. Whereas threshold stress is increased about $130 \%$ and HDPE behaves like a brittle polymer at high strain rates. 
(a)

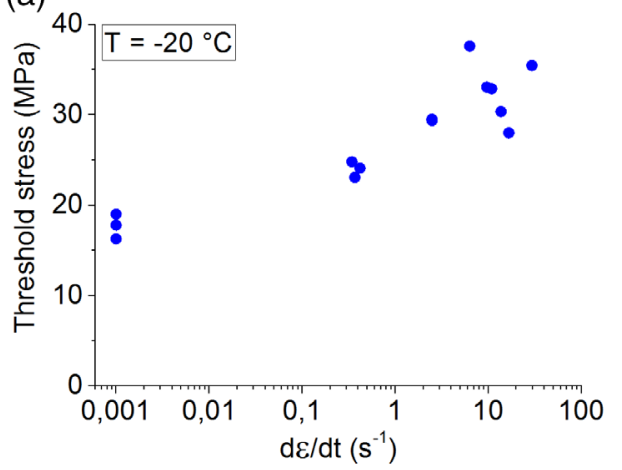

(c)

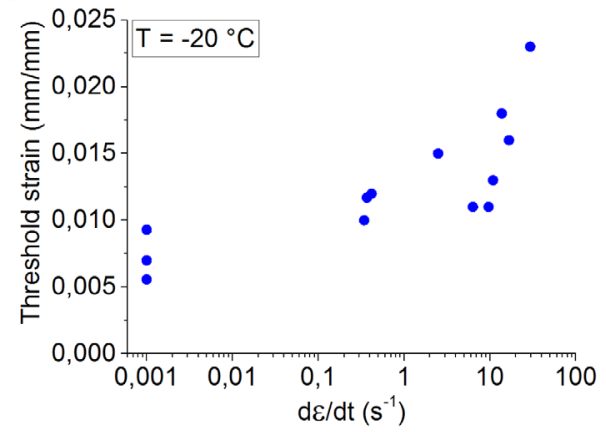

(b)

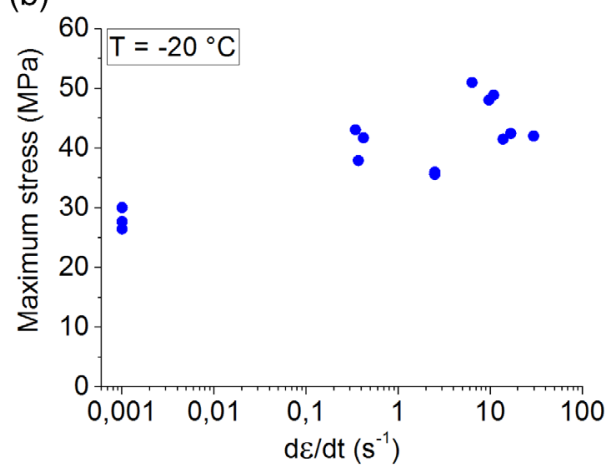

(d)

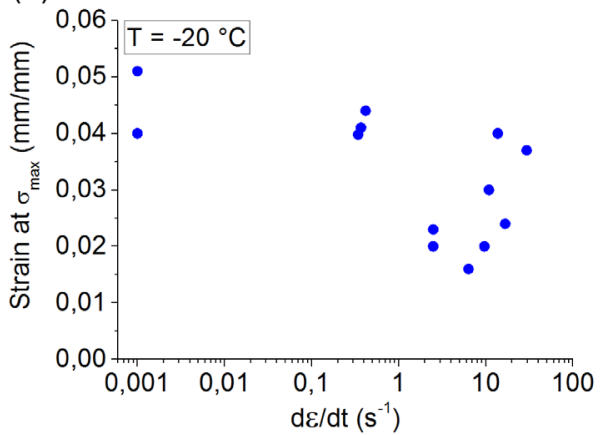

Figure 16. Influence of strain rate on the (a) threshold stress, (b) maximum stress, (c) threshold strain, and (d) strain at maximum stress. [Color figure can be viewed at wileyonlinelibrary.com]
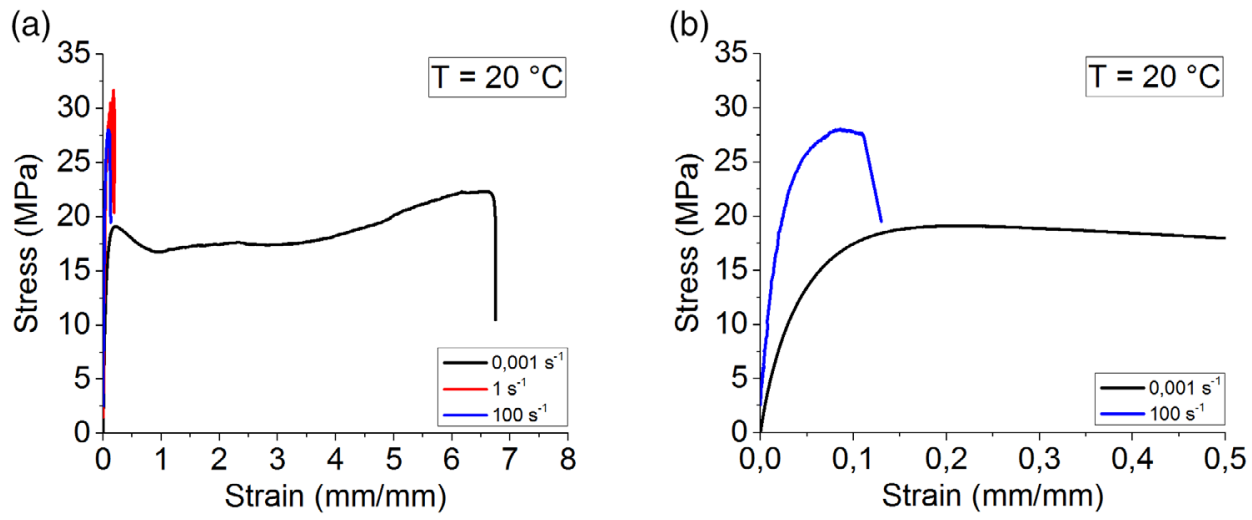

Figure 17. (a) Representative curves of the different strain rates tensile tests at $20{ }^{\circ} \mathrm{C}$ and (b) comparison of $\mathrm{E}$ at different strain rates by zoom of the left curve. [Color figure can be viewed at wileyonlinelibrary.com]

Strain rate effect at $20^{\circ} \mathrm{C}$. Stress-strain $(\sigma-\varepsilon)$ tensile curves for several strain rates at $20^{\circ} \mathrm{C}$ are presented in Figure 17. These indicate the general behavior of HDPE is influenced by loading rate at this temperature. Indeed, under rapid tensile loading, that is, $100 \mathrm{~s}^{-1}$, at $20^{\circ} \mathrm{C}$, the HDPE exhibit with the high knee point and material failure that occurs rapidly after the first step. In contrast of the quasistatic curves, these of the high strain rates at the beginning of the second step, have a delay of the knee point and an ultimate stress. By increasing the strain rate to $100 \mathrm{~s}^{-1}$, the failure strain decreases from of 7 to about $0.1 \mathrm{~mm} / \mathrm{mm}$, indicating that the material exhibits brittle behavior.

In contrast of $-20^{\circ} \mathrm{C}$, at ambient temperature, the increase of the Young's modulus can be observed at high strain rates, Figure 17(b).

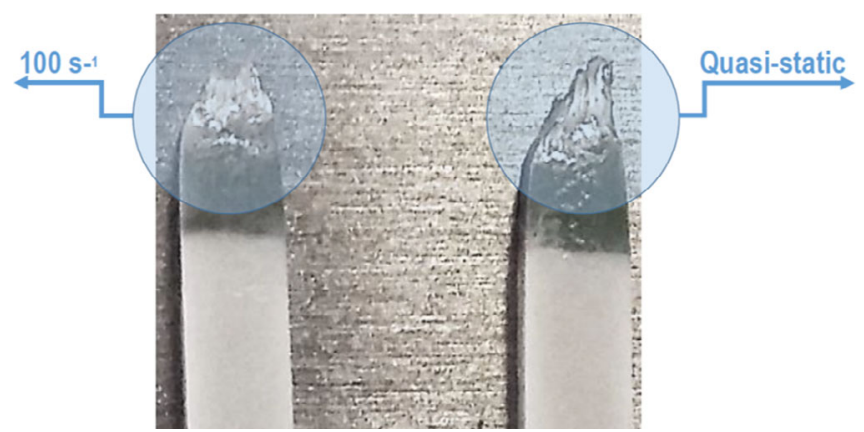

Figure 18. Macroscopic observations of fractured samples at different strain rates; quasistatic test and strain rate of $100 \mathrm{~s}^{-1}$. [Color figure can be viewed at wileyonlinelibrary.com] 

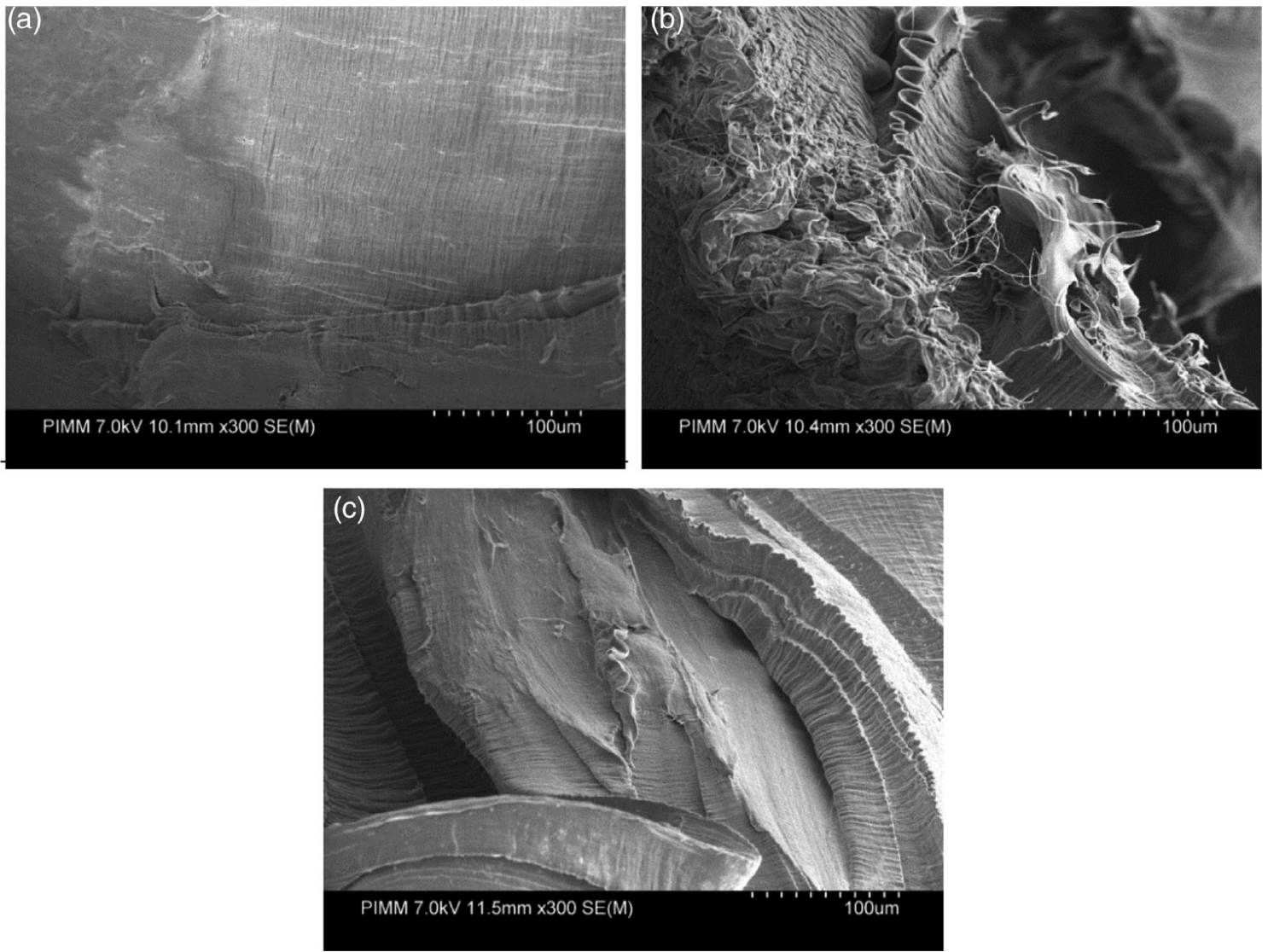

Figure 19. Fractured surfaces of the samples: (a) after the quasistatic tensile test, (b) after the loading at $1 \mathrm{~s}^{-1}$, and (c) after the high strain rate tensile tests $\left(100 \mathrm{~s}^{-1}\right)$

Figure 18 indicates the effect of the strain rate on the macroscopic extent of the HDPE fracture surface. In the quasistatic tensile test, a large amount of plastic flow of the polymer prior to the ultimate fracture appears.

Comparing the curves of Figure 17 and the macroscopic images of Figure 18, one can notice indeed that as the strain rate increased failure mode changed from quasiductile to brittle. Also, the failure of the sample subjected to high strain rate tensile test is accompanied by fragmentation.

To illustrate this change of the fracture mode, from ductile to fragile, we also examine the samples on a microscopic scale. The micrographs presented in Figure 19 show the microscopic surfaces resulted respectively after a quasistatic tensile test and another at a high strain rate, $100 \mathrm{~s}^{-1}$. These micrographs indicate that a high strain rate leads to a brittle fracture, contrary to what is observed at quasistatic loads.

In comparison to Figure 19(a), one can observe in Figure 19(c), a large amount of crack initiation and plastic deformations occurs. The distances between the rivers increase by the strain rate and of change of the fracture mode at the brittle.

\section{CONCLUSION}

The chief objective of a present article is to improve the knowledge of the properties of HDPE at molten and solid states. In this paper, the following conclusions can be quoted:
- The viscosity of HDPE does not change significantly for a shear rate of less than $0.1 \mathrm{~s}^{-1}$. Then, this one decreases gradually, for a value between 0.1 and $3 \mathrm{~s}^{-1}$ and strongly for a rate greater than $10 \mathrm{~s}^{-1}$. In addition, this viscosity decreases significantly when the temperature increases. Using the results of thermal and rheological analysis, the extrusion parameters were defined as follow: a total flow rate of $500 \mathrm{~g} / \mathrm{h}$ with a screw speed of $150 \mathrm{rpm}$ and a temperature of $220^{\circ} \mathrm{C}$. For injection process, the temperature is set at $230{ }^{\circ} \mathrm{C}$ with an injection speed of $15 \mathrm{~mm} / \mathrm{s}$.

- HDPE studied obeys the time-temperature similarity principle.

- Variation of the temperature from -20 to $20{ }^{\circ} \mathrm{C}$ leads to an abrupt reduction of the Young's modulus. This one varies from 2000 to $310 \mathrm{MPa}$, nearly 6.5 times, while break stress decreased by $30 \%$. This corresponding effect on break strain is more significant, reaches nearly 50 times initial value. One can note that increasing strain rate will decrease the molecular mobility of the HDPE chains by making the chains stiffer.

- At high strain rates, one can observe the increase of Young's modulus at ambient temperature comparatively to $-20^{\circ} \mathrm{C}$. By increasing the strain rates of tensile tests from quasistatic to highspeed loading, the mechanism of fracture changes of ductile to a brittle state.

\section{CONFLICT OF INTEREST}

This study has no funding, and the authors declare they have no conflict of interest. 


\section{REFERENCES}

1. Abdolrasouli, M. H.; Nazockdast, H.; Sadeghi, G. M. M.; Kaschta, J. J. Appl. Polym. Sci. 2015, 132, 41300.

2. Bergstrom, J. S. Mechanics of Solid Polymers: Theory and Computational Modeling; Elsevier Science: San Diego, USA, 2015.

3. Elleuch, R.; Taktak, W. J. Mater. Eng. Perform. 2006, 15 (1), 111.

4. Merah, N.; Saghir, F.; Khan, Z.; Bazoune, A. Plast. Rubber Compos. 2006, 35(4), 226.

5. Fortelny', I.; Hlavatá, D.; Horák, Z.; Kolarík, J.; Sikora, A. Blending. In Processing and Finishing of Polymeric Materials. John Wiley \& Sons; Seidel, A., Ed., Inc.: Hoboken, 2011. p. 86.

6. Daniels, D. R.; McLeish, T. C. B.; Crosby, B. J.; Young, R. N.; Fernyhough, C. M. Macromolecules. 2001, 34, 7025.

7. Kismet, Y.; Wagner, M. H. J. Polym. Eng. 2016, 37, 287.

8. Inkson, N. J.; Graham, R. S.; McLeish, T. C. B.; Groves, D. J.; Fernyhough, C. M. Macromolecules. 2006, 39, 4217.

9. Ahmadi, M.; Bailly, C.; Keunings, R.; Nekoomanesh, M.; Arabi, H.; Van Ruymbeke, E. Macromolecules. 2011, 44, 647.

10. Kismet, Y.; Wagner, M. H. Adv. Polym. Technol. 2018, 37, 3511.

11. Piel, C.; Stadler, F. J.; Kaschta, J.; Rulhoff, S.; Münstedt, H.; Kaminsky, W. Macromol. Chem. Phys. 2006, 207, 26.
12. Kismet, Y.; Wagner, M. H. Mater. Sci. Eng. Technol. 2019, $50,25$.

13. Dennis, M. Poly(methyl methacrylate) by Solution Viscosity and Viscoelastic Spectroscopy. In Introduction to Industrial Polyethylene: Properties, Catalysts and Processes, 2010.

14. Kismet, Y. Polymers. 2017, 9, 384.

15. García-Franco, C. A.; Srinivas, S.; Lohse, D. J.; Brant, P. Macromolecules. 2001, 34, 3115.

16. Keßner, U.; Kaschta, J.; Münstedt, H. J. Rheol. (N. Y. N. Y). 2009, 53, 1001.

17. Chen, W.; Lu, F.; Cheng, M. Poly. Test. 2002, 21(2), 113.

18. Richeton, J.; Ahzi, S.; Vecchio, K.; Jiang, S.; Adharapurapu, F. C.; Adharapurapu, R. R. Int. J. Solids Struct. 2006, 43(7-8), 2318.

19. Kolsky, H. Proc. Phys. Soc. 1949, 62, 676.

20. Chou, S. C.; Robertson, K. D.; Rainey, J. H. Exp. Mech. 1973, 13, 422.

21. Briscoeb, B. J.; Nosker, R. W. Polym. Commun. 1973, 26, 307.

22. Milisavljević, J.; Petrović, E.; Ćirić, I.; Mančić, M.; Marković, D.; Đorđević, M. “Tensile Testing for Different Types of Polymers", DAS-29, 29th Danubia-Adria Symposium; University of Belgrade: Serbia, 2012.

23. Mulliken, A. D.; Boyce, M. C. Int. J. Solids Struct. 2006, 43, 1331. 